\title{
Brain stimulation for combating Alzheimer's disease
}

\author{
Niels Hansen* \\ Department of Neurophysiology, Medical Faculty, Ruhr University Bochum, Bochum, Germany \\ *Correspondence: niels.hansen@rub.de \\ Edited by: \\ Haung Yu, Columbia University, USA \\ Reviewed by: \\ Haung Yu, Columbia University, USA \\ M. Mallar Chakravarty, Centre for Addiction and Mental Health, Canada \\ Abid Hussaini, Columbia University Medical Center, USA
}

Keywords: Alzheimer's disease, brain stimulation, cognition, memory, dorsolateral prefrontal cortex, transcranial magnetic stimulation, transcranial direct current stimulation, deep-brain stimulation

Alzheimer's disease $(\mathrm{AD})$ is a devastating disease affecting 5.2 million Americans. As the cause of death between 2000 and 2010, $\mathrm{AD}$ increased by $68 \%$ (1). The number of individuals developing $\mathrm{AD}$ in the United States will rise dramatically in the following decades (2). As $\mathrm{AD}$ patients are often resistant to pharmacotherapy, alternative therapeutic strategies are imperative. Noninvasive and non-lesional brain stimulation is a promising therapeutic option that has been attracting increasing attention over the last few years (3-6). Brain stimulation is useful to accelerate diagnosis and treatment $(6,7)$. This article focuses on advances in cognitive neurorehabilitation via brain stimulation techniques in $\mathrm{AD}$ patients to provide insights into a promising ray of hope for $\mathrm{AD}$ patients.

\section{NON-INVASIVE BRAIN STIMULATION TRANSCRANIAL MAGNETIC STIMULATION}

Transcranial magnetic stimulation (TMS) modulates cortical activity non-invasively (4). Repetitive transcranial magnetic stimulation (rTMS) creates magnetic pulses to the scalp delivered through a coil at a rhythmic repetition rate. The magnetic pulse causes cortical neurons to depolarize (8). TMS is an important cortical stimulation method for the adjunctive treatment of neurodegenerative disorders such as Parkinson's disease (9). Furthermore, TMS can improve cognitive function in neuropsychiatric disorders (10). RTMS studies revealed the pivotal role of the prefrontal cortex (PFC) during information encoding and retrieval (11-15). Furthermore, as neuroimaging studies revealed, heightened activity in the dorsolateral PFC (DLPFC) is one of the brain abnormalities associated with $\mathrm{AD}(16,17)$. These changes in brain activity in the DLPFC underpin the recruitment of compensatory networks $(18,19)$. It would thus make sense to modulate the PFC's neural activity to modify memory function, the most prominent feature of disturbed cognition in AD. There is solid evidence that highfrequency rTMS over the DLPFC is superior to low-frequency rTMS in treating cognitive dysfunction in $\mathrm{AD}$ patients as measured by the mini mental state examination (MMSE) (20). The first studies using TMS in AD showed that high-frequency rTMS of the DLPFC improves naming accuracy. Demented patients often display impaired naming ability (21). RTMS improved both action and object naming in a group of advanced $\mathrm{AD}$ patients $(22,23)$. Auditory verbal comprehension of continuous daily DLPFC-rTMS over 4 months was increased for up to 2 months after stimulation (24). As the inferior PFC plays a role in controlling memory (25), stimulating that part of the PFC in $\mathrm{AD}$ patients is a reasonable approach. Indeed, stimulation of the left inferior PFC resulted in enhanced episodic memory function (26). Alongside the PFC, the parietal cortices are important for information retrieval (27). RTMS of the parietal cortex advances the associative memory capacity in patients with mild cognitive impairment (MCI) (15). The combination of cognitive training with rTMS seems to benefit cognitive functions as much as treatment with cholinesterase inhibitors $(28,29)$. Moreover, TMS is useful for identifying early $\mathrm{AD}$ patients with cholinergic degeneration (30), and for monitoring the drug response (7). The biomarker of central cholinergic activity such as short-latency afferent inhibition (SAI) assessed by TMS is relevant to the drug response (31). Other TMS measures such as long-interval intracortical inhibition (LICI) are also worth considering for measuring drugs. Patients undergoing monotherapy or combination therapy with acetylcholinesterase inhibitors demonstrated impaired LICI when compared to healthy controls (7). Remarkably, the LICI values correlated with Alzheimer's Disease Assessment Scale-Cognitive Subscale (ADAS-Cog) scores. These findings indicate that these neurophysiologic TMS parameters help us measure the response to anti-dementia drugs (7).

\section{TRANSCRANIAL DIRECT CURRENT STIMULATION}

Transcranial direct current stimulation is a non-invasive tool to modulate cortical excitability via brain polarization with weak direct currents (3), and it is attracting greater attention in $\mathrm{AD}$ as a reinforcer of cognitive function (6). tDCS showed already promising results for its beneficial usage in both neurodegenerative and neuropsychiatric disorders (9, 10). The direct current affects the resting membrane potential and thereby the neuronal firing rate. The current's polarity determines the excitability of cortical neurons: anodal tDCS (atDCS) increases whereas cathodal tDCS (ctDCS) lowers it (3). AtDCS has usually been shown to rectify visual and word recognition memory and working memory in $\mathrm{AD}$ patients when applied over the temporal cortex and DLPFC (32-34). The effect of temporal cortex atDCS persisted up to 1 month after therapy (35). AtDCS of the DLPFC can 
alter connectivity during the resting state (36). This might have diagnostic value, as $\mathrm{AD}$ patients' resting-state brain electroencephalographic rhythms differ from those in control subjects (37). However, despite the obvious advantages of TMS and tDCS, both are limited to stimulating large surface cortical structures, so that the hippocampus and mediotemporal lobe structures are not accessed directly.

\section{TRANSCUTANEOUS ELECTRICAL NERVE STIMULATION}

On the contrary, transcutaneous electrical nerve stimulation (TENS) is believed to stimulate the hippocampus relevant to memory formation and the forebrain system degenerated in AD (38). TENS entails current applied transcutaneously to excite nerves, enhancing cognition in $\mathrm{AD}$ patients $(38,39)$. The hippocampus is stimulated by TENS via spinoseptal and brainstem nuclei such as the locus coeruleus (LC) and dorsal raphe nucleus (DRN) (38). The cholinergic basal forebrain system is reached by the LC and DRN via noradrenergic and serotonergic projections. TENS can induce noradrenergic and serotonergic neuromodulation by this means. There is ongoing debate as to whether the effect of TENS is more prominent in mildly or severely affected AD patients $(38,39)$. TENS is effective in improving visual memory, long-term face recognition memory, and word fluency in $\mathrm{AD}$ patients (40).

\section{VAGUS NERVE STIMULATION}

Vagal nerve (VN) afferents reach the nucleus of the solitary tract (NST), and the LC is downstream to the NST. The VN's influence on LC neurons is demonstrated by the fact that VN stimulation (VNS) induces a significant noradrenaline increase in the rat's hippocampus (41). VNS improves cognitive function as measured by the ADAS-cog and MMSE in $\mathrm{AD}$ patients (42), $\mathrm{AD}$ patients demonstrated improvement or their cognitive function did not decline even a year after VNS according to the ADAS-cog and MMSE (43).

\section{RADIO ELECTRIC ASYMMETRIC AND CEREBELLAR THETA BURST BRAIN STIMULATION}

Radio electric asymmetric and cerebellar theta burst stimulation are two novel methods. Non-invasive radio electric asymmetric brain stimulation (REAC) uses frequency ranges of $2-11 \mathrm{~Hz}$ and consists of intermittent radio-frequency bursts lasting $500 \mathrm{~ms}$ (44). REAC enhances cognitive functions in $\mathrm{AD}$ patients according to different scales [MMSE, neuropsychiatric inventory (NPI), activities of daily living (ADL), and instrumental activities of daily living (IADL)] (44). A recent study revealed that cerebellar theta burst stimulation can restore cholinergic dysfunction in $\mathrm{AD}$ patients (45). They also showed that cerebellum stimulation might be a useful tool to improve cholinergic dysfunction in $\mathrm{AD}$ via the cerebello-thalamo-cortical pathway (45) so relevant to cognitive control (46).

\section{INVASIVE BRAIN STIMULATION DEEP-BRAIN STIMULATION}

Deep-brain stimulation (DBS) consists of administering rectangular current pulses into target brain structures [for review, see Ref. (5)]. The stimulation electrodes are implanted chronically. DBS is an established therapeutic option in Parkinson's disease, dystonia, and tremor $(47,48)$. DBS has evolved to be one of the most effective treatments in Parkinson disease (49). Considering the increasing success of this technology in modulating activity in dysfunctional motor pathways, DBS is also attracting growing interest for modulating the activity in dysfunctional neural circuits in AD (5). An advantage of DBS is that memory structures can be assessed directly, unlike non-invasive brain stimulation. Bilateral DBS of the hypothalamus and fornix has led to improved recollection in memory functions (50), whereas high-frequency DBS of the fornix was clinically ineffective despite the observation of increased metabolic activity in temporal lobe structures (51). Fornix-DBS stabilized memory function in $\mathrm{AD}$ patients in tests such as the MMSE, ADAS-Cog, Free and Cued Selective Reminding Test (52). High resolution positron emission tomography studies revealed a persistent fornix-DBS effect on cerebral metabolism in memory processing structures 1 year after stimulation that correlated with improved cognitive and memory functions (53). DBS of the entorhinal cortex can induce phase resetting of hippocampal theta oscillations in humans (54). Theta resetting can enhance the encoding of new information and enhance memory (55). DBS of the entorhinal area thus seems to be a promising target in treating pathological $\mathrm{AD}$ to enhance memory functions. DBS probably reduces memory dysfunction by promoting the physiological conditions and patterns of extracellular field potentials necessary for long-term memory (56). Furthermore, there is evidence in rodents that fornix and perforant path stimulation increases hippocampal neurogenesis and long-term potentiation to facilitate memory storage $(5,57,58)$. The nucleus basalis of Meynert (NBM) has several cholinergic projections, and it degenerates in $\mathrm{AD}$, thus the NBM is a budding future target for $\mathrm{DBS}$ in $\operatorname{AD}(5,59)$. Another auspicious, but not yet investigated target of DBS in $\mathrm{AD}$ patients may be stimulation of the anterior thalamic nucleus, as prior to encoding, its stimulation improved verbal memory in epileptic patients (60). Whether bilateral or unilateral stimulation is more effective to enhance memory remains unresolved (50, 54). Moreover, the precise timing of DBS seems to be a key factor, as neurorehabilitation studies (61) have suggested that therapeutic intervention is most beneficial when applied during the learning or recall phase.

\section{CONTRASTING JUXTAPOSITION OF THE STIMULATION TECHNIOUES}

Taken together, TMS is the most frequently investigated and powerful noninvasive brain stimulation technique in $\mathrm{AD}$ patients on the basis of studies with different stimulation sites (Table 1). The DLPFC is the most evaluated stimulation target in AD patients for TMS (Table 1). tDCS and TMS offer the advantage of a non-invasive treatment and long-lasting effect. tDCS is less investigated than TMS in AD patients (Table 1). In my opinion, VNS and TENS represent also valuable, but less examined techniques that may be relevant to treating AD patients when TMS and tDCS are ineffective. Novel techniques such as REAC and cerebellar theta burst stimulation require more investigation to assess their efficacy in $\mathrm{AD}$ patients. However, these non-invasive techniques cannot be applied directly to structures involved in AD pathophysiology such as the NBM and hippocampus. DBS constitutes a valuable method for this purpose. DBS of the fornix and entorhinal area enables the modulation of memory 
Table 1 | Brain stimulation in Alzheimer's disease patients: stimulation sites and clinical effects

\begin{tabular}{|c|c|c|c|}
\hline Stimulation site & Technique & Clinical effect & Reference \\
\hline Cerebellum & TBS & Cholinergic dysfunction $\downarrow$ & $(45)$ \\
\hline \multirow[t]{5}{*}{ DLPFC } & TMS & MMSE $\uparrow$ & $(20)$ \\
\hline & TMS & Naming accuracy $\uparrow$ & $(22,23)$ \\
\hline & TMS & Auditory verbal comprehension $\uparrow$ & (24) \\
\hline & tDCS & Working memory $\uparrow$ & $(32)$ \\
\hline & tDCS & Declarative memory $\uparrow$ & (62) \\
\hline Ear & REAC & MMSE, NPI, (I)ADL $\uparrow$ & (44) \\
\hline \multirow[t]{2}{*}{ Fornix } & DBS & MMSE, ADAS-Cog, FCSR Test $\uparrow$ & $(52)$ \\
\hline & DBS & $\begin{array}{l}\text { Increased cerebral glucose } \\
\text { metabolism, memory } \uparrow\end{array}$ & (53) \\
\hline Hypothalamus and fornix & DBS & Memory recollection $\uparrow$ & $(50)$ \\
\hline Inferior PFC & TMS & Memory $\uparrow$ & (26) \\
\hline Parietal cortex & TMS & Associative memory $\uparrow$ & (15) \\
\hline \multirow[t]{2}{*}{ Spine (Th1-Th5) } & TENS & Visual memory $\uparrow$ & $(40)$ \\
\hline & & Face recognition memory $\uparrow$ & \\
\hline Temporal cortex & tDCS & Visual recognition memory $\uparrow$ & $(33,35)$ \\
\hline Temporoparietal area & tDCS & Recognition memory $\uparrow$ & (34) \\
\hline Vagus nerve & VNS & ADAS-cog and MMSE $\uparrow$ & (43) \\
\hline
\end{tabular}

ADAS-cog, Alzheimer's Disease Assessment Scale-cognitive subscale; DBS, deep-brain stimulation; DLPFC, dorsolateral prefrontal cortex; FCSR, Free and Cued Selective Reminding Test; (I) ADL, instrumental activities of daily living; MMSE, Mini Mental State Examination; NPI, neuropsychiatric inventory; $\mathrm{PFC}$, prefrontal cortex; REAC, radio electric asymmetric brain stimulation; TBS, theta burst stimulation; tDCS, transcranial direct current stimulation; TENS, transcutaneous nerve stimulation; TMS, transcrania magnetic stimulation; VNS, vagus nerve stimulation; $\uparrow$, beneficial effect; $\downarrow$, no beneficial effect.

functions. Due to its invasiveness, DBS may eventually be the ultima ratio in clinical settings if non-invasive stimulation such as TMS has not proven effective. However, given the therapeutic success of DBS in Parkinson's disease, DBS in AD is also likely to become an upcoming alternative to pharmacotherapy. In the future, individual patient characteristics with risks and potential comorbidity profiles will have to be analyzed to determine the optimal stimulation technique for that patient.

\section{CONCLUSION}

Having analyzed results from different techniques and stimulation sites, I believe that TMS, tDCS, and DBS are the brain stimulation methods with the brightest prospects in $\mathrm{AD}$ patients. Increased neural activity, connectivity, and synaptic plasticity in memory and cognition-related brain areas are potential mechanisms of action. Further intensive investigation is needed to implement stimulation protocols and targets in $\mathrm{AD}$ patients. The optimal stimulation therapy will have to be considered in accordance with individual patients' health predisposition, risks, and other factors.

\section{REFERENCES}

1. Thies W, Bleiler L. Alzheimer's Association. 2013 Alzheimer's disease facts and figures. Alzheimers Dement (2013) 9:208-45. doi:10.1016/j.jalz.2013. 02.003

2. Hebert LE, Weuve J, Scherr PA, Evans DA. Alzheimer disease in the United States (2010-2050) estimated using the 2010 census. Neurology (2013) 80:1778-83. doi:10.1212/WNL.0b013e31828726f5

3. Nitsche MA, Paulus W. Excitability changes induced in the human motor cortex by weak transcranial direct current stimulation. J Physiol
(2000) 527(Pt 3):633-9. doi:10.1111/j.1469-7793. 2000.t01-1-00633.x

4. Guerra A, Assenza F, Bressi F, Scrascia F, Del Duca M, Ursini F, et al. Transcranial magnetic stimulation studies in Alzheimer's disease. Int J Alzheimers Dis (2011) 2011:263817. doi:10.4061/2011/263817

5. Hardenacke K, Shubina E, Bührle CP, Zapf A, Lenartz D, Klosterkötter J, et al. Deep brain stimulation as a tool for improving cognitive functioning in Alzheimer's dementia: a systematic review. Front Psychiatry (2013) 4:159. doi:10.3389/fpsyt. 2013.00159

6. Flöel A. tDCS-enhanced motor and cognitive function in neurological diseases. Neuroimage (2014) 85:934-47. doi:10.1016/j.neuroimage.2013.05.098

7. Brem AK, Atkinson NJ, Seligson EE, Pascual-Leone A. Differential pharmacological effects on brain reactivity and plasticity in Alzheimer's disease. Front Psychiatry (2013) 4:124. doi:10.3389/fpsyt. 2013.00124

8. Wassermann EM, Epstein C, Ziemann U, Walsh V, Paus T, Lisanby S. Handbook of Transcranial Stimulation. Oxford: Oxford University Press (2008).

9. Wu AD, Fregni F, Simon DK, Deblieck C, PascualLeone A. Non-invasive brain stimulation for Parkinson's disease and dystonia. Neurotherapeutics (2008) 5:345-61. doi:10.1016/j.nurt.2008.02. 002

10. Demirtas-Tatlidede A, Vahabzadeh-Hagh AM, Pascual-Leone A. Can non-invasive brain stimulation enhance cognition in neuropsychiatric disorders? Neuropharmacology (2013) 64:566-78. doi: 10.1016/j.neuropharm.2012.06.020

11. Sandrini M, Cappa SF, Rossi S, Rossini PM, Miniussi C. The role of prefrontal cortex in verbal episodic memory: rTMS evidence. J Cogn Neurosci (2003) 15:855-61. doi:10.1162/ 089892903322370771

12. Rossi S, Pasqualetti P, Zito G, Vecchio F, Cappa SF, Miniussi C, et al. Prefrontal and parietal cortex in human episodic memory: an interference study by repetitive transcranial magnetic stimulation. Eur J Neurosci (2006) 23:793-800. doi:10.1111/j.14609568.2006.04600.x

13. Manenti R, Tettamanti M, Cotelli M, Miniussi C, Cappa SF. The neural bases of word encoding and retrieval: a fMRI-guided transcranial magnetic stimulation study. Brain Topogr (2010) 22:318-32. doi:10.1007/s10548-009-0126-1

14. Manenti R, Cotelli M, Calabria M, Maioli C, Miniussi C. The role of the dorsolateral prefrontal cortex in retrieval from longterm memory depends on strategies: a repetitive transcranial magnetic stimulation study. Neuroscience (2010) 166:501-7. doi:10.1016/j. neuroscience.2009.12.037

15. Cotelli M, Calabria M, Manenti R, Rosini S, Maioli C, Zanetti O, et al. Brain stimulation improves associative memory in an individual with amnestic mild cognitive impairment. Neurocase (2012) 18:217-23. doi:10.1080/13554794.2011.588176

16. Bai F, Zhang Z, Watson DR, Yu H, Shi Y, Yuan $\mathrm{Y}$, et al. Abnormal functional connectivity of hippocampus during episodic memory retrieval processing network in amnestic mild cognitive impairment. Biol Psychiatry (2009) 65:951-8. doi:10. 1016/j.biopsych.2008.10.017

17. Sperling RA, Dickerson BC, Pihlajamaki M, Vannini P, LaViolette PS, Vitolo OV, et al. 
Functional alterations in memory networks in early Alzheimer's disease. Neuromolecular Med (2010) 12:27-43. doi:10.1007/s12017-009-8109-7

18. Smith GE, Pankratz VS, Negash S, Machulda MM, Petersen RC, Boeve BF, et al. A plateau in preAlzheimer memory decline: evidence for compensatory mechanisms? Neurology (2007) 69:133-9. doi:10.1212/01.wnl.0000265594.23511.16

19. Grady CL, McIntosh AR, Beig S, Craik FI. An examination of the effects of stimulus type, encoding task, and functional connectivity on the role of right prefrontal cortex in recognition memory. Neuroimage (2001) 14:556-71. doi:10.1006/nimg. 2001.0865

20. Ahmed MA, Darwish ES, Khedr EM, El Serogy YM, Ali AM. Effects of low versus high frequencies of repetitive transcranial magnetic stimulation on cognitive function and cortical excitability in Alzheimer's dementia. J Neurol (2012) 259:83-92. doi:10.1007/s00415-011-6128-4

21. Almor A, Aronoff JM, MacDonald MC, Gonnerman LM, Kempler D, Hintiryan H, et al. A common mechanism in verb and noun naming deficits in Alzheimer's patients. Brain Lang (2009) 111:8-19. doi:10.1016/j.bandl.2009.07.009

22. Cotelli M, Manenti R, Cappa SF, Geroldi C, Zanetti O, Rossini PM, et al. Effect of transcranial magnetic stimulation on action naming in patients with Alzheimer disease. Arch Neurol (2006) 63:1602-4. doi:10.1001/archneur.63.11.1602

23. Cotelli M, Manenti R, Cappa SF, Zanetti O, Miniussi C. Transcranial magnetic stimulation improves naming in Alzheimer disease patients at different stages of cognitive decline. Eur J Neurol (2008) 15:1286-92. doi:10.1111/j.1468-1331.2008. 02202.x

24. Cotelli M, Calabria M, Manenti R, Rosini S, Zanetti O, Cappa SF, et al. Improved language performance in Alzheimer disease following brain stimulation. J Neurol Neurosurg Psychiatry (2011) 82:794-7. doi:10.1136/jnnp.2009.197848

25. Rizio AA, Dennis NA. The cognitive control of memory: age differences in the neural correlates of successful remembering and intentional forgetting. PLoS One (2014) 9:e87010. doi:10.1371/ journal.pone.0087010

26. Köhler S, Paus T, Buckner RL, Milner B. Effects of left inferior prefrontal stimulation on episodic memory formation: a two-stage fMRI-rTMS study. J Cogn Neurosci (2004) 16:178-88. doi:10.1162/ 089892904322984490

27. Manenti R, Brambilla M, Petesi M, Ferrari C, Cotelli M. Enhancing verbal episodic memory in older and young subjects after non-invasive brain stimulation. Front Aging Neurosci (2013) 5:49. doi:10.3389/fnagi.2013.00049

28. Bentwich J, Dobronevsky E, Aichenbaum S, Shorer R, Peretz R, Khaigrekht M, et al. Beneficial effect of repetitive transcranial magnetic stimulation combined with cognitive training for the treatment of Alzheimer's disease: a proof of concept study. J Neural Transm (2011) 118:463-71. doi:10.1007/ s00702-010-0578-1

29. Rabey JM, Dobronevsky E, Aichenbaum S, Gonen O, Marton RG, Khaigrekht M. Repetitive transcranial magnetic stimulation combined with cognitive training is a safe and effective modality for the treatment of Alzheimer's disease: a randomized, double-blind study. J Neural Transm (2013) 120:813-9. doi:10.1007/s00702-012-0902-z

30. Pennisi G, Ferri R, Lanza G, Cantone M, Pennisi M, Puglisi V, et al. Transcranial magnetic stimulation in Alzheimer's disease: a neurophysiological marker of cortical hyperexcitability. J Neural Transm (2011) 118:587-98. doi:10.1007/s00702010-0554-9

31. Di Lazzaro V, Oliviero A, Pilato F, Saturno E, Dileone M, Marra C, et al. Neurophysiological predictors of long term response to AChE inhibitors in AD patients. J Neurol Neurosurg Psychiatry (2005) 76:1064-9. doi:10.1136/jnnp.2004.051334

32. Fregni F, Boggio PS, Nitsche M, Bermpohl F, Antal A, Feredoes E, et al. Anodal transcranial direct current stimulation of prefrontal cortex enhances working memory. Exp Brain Res (2005) 166:23-30. doi:10.1007/s00221-005-2334-6

33. Boggio PS, Khoury LP, Martins DC, Martins OE, de Macedo EC, Fregni F. Temporal cortex direct current stimulation enhances performance on a visual recognition memory task in Alzheimer disease. J Neurol Neurosurg Psychiatry (2009) 80:444-7. doi:10.1136/jnnp.2007.141853

34. Ferrucci R, Mameli F, Guidi I, Mrakic-Sposta S, Vergari M, Marceglia S, et al. Transcranial direct current stimulation improves recognition memory in Alzheimer disease. Neurology (2008) 71:493-8. doi:10.1212/01.wnl.0000317060.43722.a3

35. Boggio PS, Ferrucci R, Mameli F, Martins D, Martins $\mathrm{O}$, Vergari $\mathrm{M}$, et al. Prolonged visual memory enhancement after direct current stimulation in Alzheimer's disease. Brain Stimul (2012) 5:223-30. doi:10.1016/j.brs.2011.06.006

36. Keeser D, Meindl T, Bor J, Palm U, Pogarell O, Mulert C, et al. Prefrontal transcranial direct current stimulation changes connectivity of restingstate networks during fMRI. J Neurosci (2011) 31:15284-93. doi:10.1523/JNEUROSCI.0542-11. 2011

37. Vecchio F, Babiloni C, Lizio R, Fallani Fde V, Blinowska K, Verrienti G, et al. Resting state cortical EEG rhythms in Alzheimer's disease: toward EEG markers for clinical applications: a review. Supp Clin Neurophysiol (2013) 62:223-36. doi:10.1016/ B978-0-7020-5307-8.00015-6

38. Luijpen MW, Swaab DF, Sergeant JA, van Dijk KR, Scherder EJ. Effects of transcutaneous electrical nerve stimulation (TENS) on memory in elderly with mild cognitive impairment. Behav Brain Res (2005) 158:349-57. doi:10.1016/j.bbr. 2004.09.017

39. Guo Y, Shi X, Uchiyama H, Hasegawa A, Nakagawa $\mathrm{Y}$, Tanaka $\mathrm{M}$, et al. A study on the rehabilitation of cognitive function and short-term memory in patients with Alzheimer's disease using transcutaneous electrical nerve stimulation. Front Med Biol Eng (2002) 11:237-47. doi:10.1163/ 156855701321138905

40. Scherder EJ, Bouma A, Steen LM. Effects of "isolated" transcutaneous electrical nerve stimulation on memory and affective behavior in patients with probable Alzheimer's disease. Bio Psychiatry (1998) 43:417-24. doi:10.1016/S00063223(97)00208-4

41. Roosevelt RW, Smith DC, Clough RW, Jensen RA, Browning RA. Increased extracellular concentrations of norepinephrine in cortex and hippocampus following vagus nerve stimulation in the rat. Brain Res (2006) 1119:124-32. doi:10.1016/j.brainres.2006.08.048

42. Sjögren MJ, Hellström PT, Jonsson MA, Runnerstam M, Silander HC, Ben-Menachem E. Cognition-enhancing effect of vagus nerve stimulation in patients with Alzheimer's disease: a pilot study. J Clin Psychiatry (2002) 63:972-80. doi:10.4088/JCP.v63n1103

43. Merrill CA, Jonsson MA, Minthon L, Ejnell H, Cson Silander H, Blennow K, et al. Vagus nerve stimulation in patients with Alzheimer's disease: additional follow-up results of a pilot study through 1 year. J Clin Psychiatry (2006) 67:1171-8. doi:10. 4088/JCP.v67n0801

44. Mannu P, Rinaldi S, Fontani V, Castagna A. Radio electric asymmetric brain stimulation in the treatment of behavioral and psychiatric symptoms in Alzheimer disease. Clin Interv Aging (2011) 6:207-11. doi:10.2147/CIA.S23394

45. Di Lorenzo F, Martorana A, Ponzo V, Bonní S, D'Angelo E, Caltagirone C, et al. Cerebellar theta burst stimulation modulates short latency afferent inhibition in Alzheimer's disease patients. Front Aging Neurosci (2013) 5:2. doi:10.3389/fnagi.2013. 00002

46. Ide JS, Li CS. A cerebellar thalamic cortical circuit for error-related cognitive control. Neuroimage (2011) 54:455-64. doi:10.1016/j.neuroimage. 2010.07.042

47. Deuschl G, Schade-Brittinger C, Krack P, Volkmann J, Schäfer H, Bötzel K, et al. Neurostimulation section. A randomized trial of deep brain stimulation for Parkinson's disease. N Engl J Med (2006) 355:896-908. doi:10.1056/NEJMoa060281

48. Kupsch A, Benecke R, Müller J, Trottenberg T, Schneider GH, Poewe W, et al. Deep-brain stimulation for dystonia study group. Pallidal deep-brain stimulation in primary generalized or segmental dystonia. N Engl J Med (2006) 355:1978-90. doi:10.1056/NEJMoa063618

49. Deuschl G, Paschen S, Witt K. Clinical outcome of deep brain stimulation for Parkinson's disease. Handb Clin Neurol (2013) 116:107-28. doi:10. 1016/B978-0-444-53497-2.00010-3

50. Hamani C, McAndrews MP, Cohn M, Oh M, Zumsteg D, Shapiro CM, et al. Memory enhancement induced by hypothalamic/fornix deep brain stimulation. Ann Neurol (2008) 63:119-23. doi:10.1002/ ana. 21295

51. Laxton AW, Tang-Wai DF, McAndrews MP, Zumsteg D, Wennberg R, Keren R, et al. A phase I trial of deep brain stimulation of memory circuits in Alzheimer's disease. Ann Neurol (2010) 68:521-34. doi:10.1002/ana.22089

52. Fontaine D, Deudon A, Lemaire JJ, Razzouk M, Viau P, Darcourt J, et al. Symptomatic treatment of memory decline in Alzheimer's disease by deep brain stimulation: a feasibility study. J Alzheimers Dis (2013) 34:315-23. doi:10.3233/JAD- 121579

53. Smith GS, Laxton AW, Tang-Wai DF, McAndrews MP, Diaconescu AO, Workman CI, et al. Increased cerebral metabolism after 1 year of deep brain stimulation in Alzheimer disease. Arch Neurol (2012) 69:1141-8. doi:10.1001/archneurol.2012. 590

54. Suthana N, Haneef Z, Stern J, Mukamel R, Behnke E, Knowlton B, et al. Memory enhancement and 
deep-brain stimulation of the entorhinal area. N Engl J Med (2012) 366:502-10. doi:10.1056/ NEJMoa 1107212

55. Vinogradova OS, Brazhnik ES, Kichigina VF, Stafekhina VS. Modulation of the reaction of hippocampal neurons to sensory stimuli by cholinergic substances. Neurosci Behav Physiol (1996) 26:113-24. doi:10.1007/ BF02359414

56. Lee H, Fell H, Axmacher N. Electrical engram: how deep brain stimulation affects memory. Trends Cogn Sci (2013) 17:574-84. doi:10.1016/j.tics. 2013.09.002

57. Blaise JH, Hartman RA. Stimulation of perforant path fibers induces LTP concurrently in amygdala and hippocampus in awake freely behaving rats. Neural Plast (2013) 2013:565167. doi:10. $1155 / 2013 / 565167$

58. Jungenitz T, Radic T, Jedlicka P, Schwarzacher SW. High-frequency stimulation induces gradual immediate early gene expression in maturing adult-generated hippocampal granule cells. Cereb Cortex (2013). doi:10.1093/cercor/bht035

59. Gratwicke J, Kahan J, Zrinzo L, Hariz M, Limousin P, Foltynie T, et al. The nucleus basalis of Meynert: a new target for deep brain stimulation in dementia? Neurosci Biobehav Rev (2013) 37:2676-88. doi:10.1016/j.neubiorev.2013. 09.003

60. Oh YS, Kim HJ, Lee KJ, Kim YI, Lim SC, Shon YM. Cognitive improvement after long-term electrical stimulation of bilateral anterior thalamic nucleus in refractory epilepsy patients. Seizure (2012) 21:183-7. doi:10.1016/j.seizure.2011.12.003

61. Murphy TH, Corbett D. Plasticity during stroke recovery: from synapse to behaviour. Nat $\mathrm{Rev} \mathrm{Neu-}$ rosci (2009) 10:861-72. doi:10.1038/nrn2735

62. Javadi AH, Walsh V. Transcranial direct current stimulation ( $t D C S$ ) of the left dorsolateral prefrontal cortex modulates declarative memory. Brain Stimul (2012) 5:231-41. doi:10.1016/j.brs. 2011.06.007
Conflict of Interest Statement: The author declares that the research was conducted in the absence of any commercial or financial relationships that could be construed as a potential conflict of interest.

Received: 24 March 2014; accepted: 10 May 2014; published online: 02 June 2014.

Citation: Hansen N (2014) Brain stimulation for combating Alzheimer's disease. Front. Neurol. 5:80. doi: 10.3389/fneur.2014.00080

This article was submitted to Neurodegeneration, a section of the journal Frontiers in Neurology.

Copyright $\odot 2014$ Hansen. This is an open-access article distributed under the terms of the Creative Commons Attribution License (CC BY). The use, distribution or reproduction in other forums is permitted, provided the original author(s) or licensor are credited and that the original publication in this journal is cited, in accordance with accepted academic practice. No use, distribution or reproduction is permitted which does not comply with these terms. 